\title{
Nutrition transition in Vietnam: changing food supply, food prices, household expenditure, diet and nutrition outcomes
}

\author{
Jody Harris ${ }^{1,2}$ (D) Phuong Hong Nguyen ${ }^{3} \cdot$ Lan Mai Tran ${ }^{4} \cdot$ Phuong Nam Huynh ${ }^{5}$
}

Received: 8 April 2019 / Accepted: 17 August 2020 / Published online: 1 September 2020

(C) The Author(s) 2020

\begin{abstract}
While literature has noted the presence of a nutrition transition in terms of changing nutrition outcomes in Vietnam, very limited evidence linking changes in upstream food system factors to downstream diet and nutrition changes exists. Combining available data from different sources and analyzing it through a conceptual food systems framework, our study examines different pathways of nutrition transition through food supply, food prices, household food expenditures, diets, and nutrition outcomes in Vietnam. Our findings show that while Vietnam is at the start of its nutrition transition, change is happening rapidly. Undernutrition is falling, obesity is rising, and nutrition-related chronic diseases account for a significant burden of diseases and death. In terms of changes in healthful foods, the supply of vegetables and fruits is plentiful, and expenditure on vegetables remains consistent and small. Notably however, vegetable consumption has dropped, and increasing meat and milk consumption have been double-edged swords for nutrition. In terms of foods associated with the negative sides of the nutrition transition, the availability of sweets and sweetened beverages has risen in recent years, with oils and fats rising less. The expenditure share on food eaten away from home, in many contexts a marker for less healthful diets, has increased over time. While these changes are typical of a nutrition transition, Vietnam is also somewhat of an outlier in some respects: wet markets and daily fresh food purchases continue to dominate food purchasing behaviour, and food eaten away from home means a different thing in a country renowned for its diverse and healthy street food and roadside restaurant culture. While this study brings together important data on the food system drivers of a nutrition transition in Vietnam, it cannot link each of these issues into a standard statistical model of change due to data gaps at different levels, calling for data collection improvement in future diet and food systems research. Vietnamese health policy explicitly acknowledges nutrition transition issues, with targets for obesity reduction. This work on the food system drivers of the nutrition transition points to the need to further adapt policy in other sectors beyond health, however. At the same time as making nutrient-rich foods more accessible, nutrient-poor or ultra-processed foods need to be made less accessible and desirable if additional income is to contribute to a healthy diet in limiting Vietnam's emerging nutrition transition.
\end{abstract}

Keywords Vietnam $\cdot$ Nutrition transition $\cdot$ Food system $\cdot$ Policy

Jody Harris

j.harris@ids.ac.uk

1 Institute of Development Studies at the University of Sussex, Brighton, UK

2 World Vegetable Center, Bangkok, Thailand

3 International Food Policy Research Institute, Washington, DC, USA

4 FHI 360, Hanoi, Vietnam

5 National Institute of Nutrition, Hanoi, Vietnam

\section{Introduction}

The past several decades have seen significant changes in food systems, diets and related health issues around the world. Over different time scales in different places, many populations have moved from traditional diets (involving locally-specific coarse grains, pulses, fruits and vegetables, and some meat or fish largely depending on season) towards a standardized global diet with increasing levels of animal foods, fat, sugar and processed packaged foods (Kennedy et al. 2004; Pingali 2004; Mehio Sibai et al. 2010; Misra et al. 2011; Baker and Friel 2014).

Changing diets are associated with rising levels of nutritionrelated chronic diseases such as obesity, diabetes, hypertension and cardiovascular diseases, and some cancers. These changes often occur at the same time as persistent undernutrition, and very 
often also micronutrient deficiencies, creating a double- or tripleburden of nutrition issues (Popkin 1994; Black et al. 2013; Gillespie and van den Bold 2017). These nutrition-related chronic diseases are now a larger issue for adults than undernutrition in a majority of the world: non-communicable diseases (NCDs) have become the leading cause of death globally, and over $75 \%$ of deaths from NCDs occur in low- and middle-income countries (Imamura et al. 2015; Cook 2017; Afshin et al. 2019). This pattern of dietary changes and associated nutrition and health outcomes has been described as a 'nutrition transition', and with some regional and national nuance has now been documented all over the world (Popkin 1994; Popkin 2014).

Much of the literature on the nutrition transition has focused on the interactions between changing economics and demographics (largely framed as processes of globalisation) and changing diets, nutrition profiles and chronic disease burdens (Kennedy et al. 2004; Hawkes 2006). There have been fewer studies looking at what happens in the space between economic and demographic change and these dietary outcomes, which is largely taken up by the food system (Harris et al. 2019), Different supply- and demand-side pressures within food systems are changing diets at a rapid pace, albeit with regional and national differences in patterns and outcomes (Hawkes 2008). There is therefore a need to understand this 'missing middle' and how changing drivers are altering food systems to produce shifting diets and the nutrition transition (Popkin 2014).

In Vietnam, several studies have noted the presence of a nutrition transition in terms of changing nutrition outcomes (Cuong et al. 2006; Nguyen et al. 2007; Khan and Khoi 2008; Van Lierop et al. 2008; Mai et al. 2020). Recent work has looked at associations with upstream factors, finding several socio-economic and health factors associated with rising obesity in Vietnam, including a $20 \%$ higher provincial average monthly per capita income associated with a $17.4 \%$ higher prevalence in child overweight or obesity (Beal et al. 2020). These factors are often available in the same datasets as diet or nutrition outcomes and so can be modelled, but food system data is usually collected separately. Very limited evidence exists, therefore, linking changes in upstream food system factors to downstream diet and nutrition changes in this country, mirroring a general lack of empirical work on the food system drivers of the nutrition transition globally. To fill this gap, this paper assesses how changing food system drivers are playing out in Vietnam's food supply, food prices, household food expenditures, diets, and nutrition outcomes.

\section{Methods}

This paper uses multiple data sources to bring together an analysis of the changes in food and nutrition in Vietnam over several decades. Because food system data usually do not occur in the same datasets as nutrition and health data, we can't undertake standard statistical analyses of the issue, but we gain a broader view through our synthetic approach which helps us to understand potential policy responses. In addition, the paper extends the scope of many epidemiological nutrition transition papers by looking at broader food system drivers of the transition. We complement our original and secondary analyses below with a review of available literature on food system drivers globally, regionally and in Vietnam, to understand the bigger picture driving change.

\subsection{Conceptual framework of food systems}

Diet and nutrition changes arise as a result of a complex interactions within the food system shaped by changes in a range of drivers, summarised in a widely-accepted food systems framework (HLPE 2017). Food system drivers have been summarised as biophysical and environmental (including natural resources and climate drivers); innovation, technology and infrastructure drivers; political and economic drivers (including globalization, trade, and prices); socio-cultural drivers (including food cultures and women's empowerment); and demographic drivers (including urbanisation and migration). These drivers shape food supply chains from production to market; food environments (including food access and affordability); and consumer behaviour in choosing what food to buy and eat. These play out in diet and nutrition outcomes, alongside social, economic and environmental impacts.

This framework guides the current study, and we have endeavoured to collect and analyse information from each section of the food system framework: Information on food system drivers globally, regionally and nationally; information on food supply as a measure of food supply chains; information on food prices as a measure of the food environment; information on household expenditures as a measure of consumer behaviour; and information on diets and changing nutrition outcomes. Note that in this paper, we use the word 'consumption' to mean the eating of foods, rather than the economic sense of buying of foods.

\subsection{Data and analysis}

Where possible, the changes in food supply, food prices, and household food expenditures are calculated using available data for 12 major food groups (cereals; tubers and roots; legumes, nuts and seeds; eggs; meat; fish and sea foods; milk and milk products; oils and fats; vegetables; fruits; sweets; and beverages) relevant to food security and nutrition recommended in understanding food and diets at the household level (FANTA 2006).

To assess changing food supply, the FAO Statistical Database on Food Balance (http://www.fao.org/faostat/en/\# data/FBS) was used to calculate 3 year averages in food supply measured as kilograms/capita/year $(\mathrm{kg} / \mathrm{c} / \mathrm{y})$. This 
food supply data compiled by FAOSTAT represents the per capita supply of food items (or food groups) available for human consumption. FAOSTAT provides several aggregate food categories. For example, the FAOSTAT food groups of meat and offal were combined into "meat" and vegetable and animal fats were combined into "oils and fats". Three year averages were calculated to demonstrate trends using the following years: 1961-1963; 1971-1973; 1981-1983; 1991-1993; 2001-2003 and 2011-2013.

To examine changing food prices, we undertook an analysis of a price dataset from FAO Annual Producer Prices (http://www.fao.org/faostat/en/\#data/PP) showing prices of different food commodities from 1996 to 2015. Individual foods representing common purchases were chosen as markers of price changes in each of the 12 FAO food groups. These prices were deflated using the FAOSTAT deflators database for Agriculture, Forestry and Fishery, using 2010 prices as a base year. For each of the foods, two price analyses were undertaken: Assessment of absolute change in price over time, to understand overall household food purchasing power; and assessment of price change relative to rice, to understand the cost of diversifying food purchases away from the staple food.

To look at changing expenditure patterns, we analysed changes in household food expenditure over a decade (2002-2014) in rural and urban Vietnam using seven rounds of the Vietnam Household Living Standards Survey (HHLSS 2002, 2004, 2006, 2008, 2010, 2012 and 2014) (General statistics office of Vietnam n.d. multiple years). This survey has been conducted regularly by the General Statistics Office every 2 years to systematically monitor the living standards of different population groups in Vietnam and to contribute to the evaluation of achievement of the Millennium Development Goals and Vietnam's socio-economic development goals. We focused on analysis of expenditures within 11 of the 12 FAO food groups (milk expenditure was not available in this dataset), with the analysis disaggregated by socioeconomic status group and by rural/urban areas. We used the expenditure share of each food item out of total food expenditure (expressed as a percentage) as an indicator of household purchases (Chisanga and Mbata-Zulu 2017).

For each of these levels of the food system (food supply, food prices, and household food expenditures), data were complemented by information available from the Euromonitor database for Vietnam (https://www. euromonitor.com/vietnam). The Euromonitor compiles and provides both raw data and summary reports for strategic market research on products and services, including foods. The reports and assessments for several key sectors (sugar and sweeteners, edible oils, fresh foods, fruits and vegetables, dairy, and packaged foods) were used to fill gaps left by other data sources.
To look at changing diets, we synthesized findings from four rounds of General Nutrition Survey (1985, 1989, 2000 and 2009) which was conducted by the National Institute of Nutrition and made publicly-available in the form of reports (raw data was not available) (Ministry of Health, National Institute of Nutrition and UNICEF 2010). The Vietnam General Nutrition Survey is used to provide scientific evidence of trends in food consumption and nutritional status, representative for all 64 provinces, over the last two decades. The report provides a snapshot of diet quality changes over time, but notably tells us little about differences between rural and urban or richer and poorer households.

Finally, to assess changing nutrition and related health outcomes in Vietnam, data on child stunting, wasting and overweight, and female underweight and overweight, were taken from national nutrition surveillance and nutrition profiles between 1999 and 2015 (National Institute of Nutrition 2015). A snapshot of nutrition-related chronic diseases is taken from a recent review of the burden of NCDs in Vietnam (Tuan T Nguyen and Hoang 2018).

\subsection{Study limitations and research needs}

None of these data sources is perfect, but each is valid data in its field, and each can tell us about some aspects of how the food system is changing in response to changing drivers, and how this is shaping the nutrition transition in Vietnam. This paper cannot link each of these issues into a single model of change as the data do not exist at all of these different levels in a form that would allow for standard statistical analysis. What this paper adds to the literature is a narrative of changes in key aspects of food and nutrition in Vietnam based on new analyses of existing data.

While this study brings together important data on the food system drivers of a nutrition transition in Vietnam, some of the data has known limitations, particularly the food balance sheet data. In particular, different foods or food groups (and different time periods) are captured under each dataset, making comparison difficult, thought broad trends are available to see. Because of these differences in metrics, there are discrepancies between the supply and intake data which merit further investigation.

While several sources of dietary data are available, intake data do not tell us about different population groups or the equity of consumption, in particular in urban and rural populations, and ethnic majority and minority groups. In addition, dietary data does not yet focus on the foods known to be associated with the nutrition transition; future surveys and studies should collect information on ultra-processed food consumption, and sugary drinks, to monitor their contribution to the nutrition transition.

This analysis reveals the gaps in information that would improve our understanding of food system and nutrition 
change, and so our ability to create relevant policy. This work also provides indicative data on food system drivers of nutrition transition, but these gaps should be followed up in subsequent work in Vietnam, particularly measuring aspects of the nutrition transition in forthcoming nutrition surveys.

\section{Results}

\subsection{Changing food system drivers}

Vietnam is increasingly integrated into global food and economic systems, so global and regional processes affect national outcomes. National-level changes build on and moderate these global trends. Vietnam has seen dramatic changes over the past four decades in several known food system drivers, reviewed below.

\subsubsection{Political and economic}

Economic growth was the key factor associated with the nutrition transition, and has remained so throughout this literature (Popkin 1994; Popkin and Gordon-Larsen 2004); recent studies have suggested that for every $10 \%$ increase in gross domestic product (GDP) per capita, child stunting reduces $6 \%$ but overweight and obesity in women rises $7 \%$ (Ruel et al. 2013). Led by the 'Asian Tiger' economies, the South-East Asian region grew richer and more globally connected in the twenty-first century; but this region is also growing more unequal, both within cities and between rural and urban areas (Schneider et al. 2015; Wei 2017). In Vietnam, GDP per capita has grown from 239 USD in 1985 to 2185 USD in 2016, with average GDP growth rates of 6-7\% in recent years (World Bank 2018), and the proportion of the population living below the poverty line has halved since 2010, standing at just under $10 \%$ in 2016. Vietnam has be lauded for translating its economic growth into broad-based human development outcomes for much of its population through widening access to education and health, where other Asian countries have not (Baulch 2016). While Vietnam has achieved a more inclusive economic growth than many countries, with the incomes of the poorest growing faster than the average, there are still significant gaps particularly between the ethnic majority and some minorities, between urban and rural populations, and between the very wealthy and the majority (Nguyen et al. 2017).

National economic growth improves the affordability of food for those swept along by the tide, but not all are raised up equally, and not all newly-affordable foods are desirable for health. In general, foods that are nutrient-dense and less processed - but more perishable and harder to transport - are more expensive in global supply systems, and processed foods with longer shelf life cost less, making higher-quality diverse diets more expensive (Ruel et al. 2008; Chicago Council on Global Affairs 2011; Crush et al. 2011; Miller et al. 2016). High-quality diets based on diverse plant foods have been shown to be too expensive for around $20 \%$ of the global population, largely in poorer countries or poorer regions of richer countries (Hirvonen et al. 2019). Income growth is therefore associated with increased purchase of highly processed foods and sugar-sweetened beverages which are seen to drive health changes associated with the nutrition transition (Global Panel on Agriculture and Food Systems for Nutrition 2016; Monteiro et al. 2018). Most households in Vietnam purchase a significant proportion of their food. Average food expenditure in Vietnam was nearly double in 2014 what it had been a decade earlier (though expenditures were also significantly more unequal across the population over that time), with fat the most responsive of the macronutrients to food prices changes, and carbohydrates the least (Trinh et al. 2019).

With economic renovation taking Vietnam from a centrally-planned command economy to a market-oriented economy from 1986, the country is now more globally connected than its nearest neighbours Cambodia and Laos PDR, though less so than Thailand and Indonesia ${ }^{1}$ (Gygli et al. 2019). Vietnam has multiple active free trade policies in place which facilitate global trade in different foods, and have few provisions for protecting public health through attention to the food environment or diets (Harris et al. forthcoming).

\subsubsection{Biophysical, technology and infrastructure}

Globally, studies have found green-revolution related changes in agriculture practices leading to higher production of grain and vegetable oils and cheaper prices on global markets, facilitating higher production of processed foods which are less perishable and therefore more exportable and tradeable (Global Panel on Agriculture and Food Systems for Nutrition 2016), in part driving the nutrition transition. In Vietnam, agricultural production systems have shifted rapidly form largely collective or smallholder models in the 1980s to larger and more commercialised systems, allowing for national sufficiency and significant exports in rice, the main staple crop (Raneri et al. 2019). Around half of Vietnam's population is directly engaged in agriculture in some form, from subsistence to commercial, though many are leaving farming as the country modernises, with around one million households having left the sector between 2011 and 2016 (Nguyen et al. 2017). Primary agriculture as a household food source is still significant, but declining, and more foreign direct investment (including zoning of parts of the countryside for mass production with modern technology) is expected in some sectors (particularly vegetables) offering a further

\footnotetext{
${ }^{1}$ According to the KOF Globalization Index of the economic, social and political dimensions of globalization.
} 
challenge to small farmers (Euromonitor International 2018a, 2018b, 2018c, 2018d, 2018e).

Modern food systems see the introduction of additional value chain actors working well beyond the traditional agriculture sector, from manufacturers to marketers to modern retail and food outlets, making, marketing and selling foods that are both healthy and unhealthy (Baker and Friel 2014; Global Panel on Agriculture and Food Systems for Nutrition 2016). The food processing industry in Vietnam has grown rapidly, which alongside global and regional trade has made most foods more available (Raneri et al. 2019).

As with other countries in the region (Kelly et al. 2014), Vietnam's food retail landscape is still dominated by traditional wet-markets for daily purchases of fresh foods, accounting for around $85 \%$ of grocery sales in 2016 (USDA Foreign Agricultural Service 2017). In urban Vietnam, of an annual per capita consumption of fruits and vegetables of $149.7 \mathrm{~kg}$ ( $23 \%$ lower in poorest; $31 \%$ higher in richest), $13 \mathrm{~kg}$ is own production (26 kg poorest, $5 \mathrm{~kg}$ richest); $125 \mathrm{~kg}$ is traditional retail ( $85 \mathrm{~kg}$ poorest, $166 \mathrm{~kg}$ richest); and only $8 \mathrm{~kg}$ is modern retail ( $0.5 \mathrm{~kg}$ poorest, $22 \mathrm{~kg}$ richest) (Mergenthaler et al. 2009). This trend is mirrored in other grocery sectors: supermarkets are a growing sector but still only reach urban and wealthier populations; informal retailing and wet markets account for the largest proportion of sales for most food groups, though sales are declining partly over food safety and cleanliness concerns and increased government control measures; and convenience stores such as the ubiquitous $7 / 11$ are filling a significant gap in the middle (Euromonitor International 2018a, 2018b, 2018c, 2018d, 2018e).

This change has implications for food sourcing, with supermarkets and convenience stores (and their international supply chains) tending to prefer supplying processed foods with longer shelf-life but generally lower nutritional quality in terms of nutrients per calorie (Rischke et al. 2015; Bloem and de Pee 2017). Market analysis suggests that the Vietnamese government is actively pursuing policies that foster closer economic and cultural ties with other countries, and predict increased availability and popularity of foreign foods (Euromonitor International 2018a, 2018b, 2018c, 2018d, 2018e); in several food sectors, Vietnamese companies are reported to be weaker and overtaken (or merged with) larger international brands (Euromonitor International 2018a, 2018b, 2018c, 2018d, 2018e; Euromonitor International 2018a, 2018b, 2018c, 2018d, 2018e).

\subsubsection{Socio-cultural and demographic}

Urbanization of populations and subsequent changes to lifestyles and food acquisition strategies, was an early factor associated with nutrition transition (Popkin 1999). Alongside increased access to both perishable fresh foods and processed packaged foods, changing preferences as a result of interactions between increasing incomes, increasing connections among people in different countries, and increasing reach of advertising and media marketing changed the most for urban populations (Pingali 2004; Hawkes et al. 2017). Other key factors associated with urbanisation include more people working outside the home and less space for food preparation, hence more reliance on convenience and street foods; and greater exposure to food marketing (Global Panel on Agriculture and Food Systems for Nutrition 2016; Miller et al. 2016).

Through the twentieth century, East Asia was the global region with the most dramatic demographic transition (lowering rates of mortality and fertility) and South-East Asia is one of the fastest-urbanizing parts of the world (Bloom and Williamson 1998). The 2009 census observed that $30 \%$ of Vietnam's population (over 25 million people) were living in urban areas, with an urban growth rate of 3.4\% (General Satistics Office of Vietnam 2009). The World Bank estimated a figure closer to $35 \%$ by 2017 (World Bank 2018).

Vietnam has a thriving and internationally-recognised food culture, with traditional foods built on a long history of integration of other cuisines, and generally seen as diverse and healthy whether eaten inside or outside of the home (Van Esterik 2008). Times are changing, however, with convenience foods and fast foods among those becoming preferred by parts of the population, whether due to convenience, aspiration or taste. The case of meat has been studied specifically in the Vietnamese context, with very rapid increases in meat consumption being driven in part by positive social connotations attached to meat as a symbol of development and progress, alongside increased prevalence of eating out and the meat-intensification of traditional meals (Hansen 2018). A key dynamic shifting food acquisition and eating cultures in recent years has been food safety concerns, from chemical and pesticide contamination, and this is a dominant food discourse in the country currently (Wertheim-Heck and Spaargaren 2016).

\subsection{Changing food supply}

The national supply of foods is a function of production and trade, and will affect what is available for households to consume. Data available are at aggregate national level, and do not account for differences in availability in different parts of the country or at different times of year.

The major staple food in Vietnam is rice, generally consumed as polished white rice or processed into noodles. Cereal availability reduced significantly between 1971 and 1993 (with roots, largely cassava, replacing cereals, largely rice), then increased to slightly higher than original levels (with roots declining again) (Table 1). 
Table 1 Supply of different food groups in Vietnam over time (3-year averages, 1961-2013) (kg/capita/year)

\begin{tabular}{|c|c|c|c|c|c|c|c|c|c|c|c|c|}
\hline (years) & Cereals & Roots & $\begin{array}{l}\text { Legumes, nuts and } \\
\text { seeds }\end{array}$ & Vegetables & Fruits & Meat & $\begin{array}{l}\text { Fish and } \\
\text { seafood }\end{array}$ & Eggs & $\begin{array}{l}\text { Milk and milk } \\
\text { products }\end{array}$ & $\begin{array}{l}\text { Oils and } \\
\text { fats }\end{array}$ & Sweets & Beverages \\
\hline $61-63$ & 159.8 & 31.7 & 3.2 & 45.0 & 36.4 & 13.0 & 15.7 & 1.5 & 2.0 & 0.7 & 7.9 & 3.7 \\
\hline $71-73$ & 160.7 & 25.2 & 3.0 & 40.1 & 34.1 & 11.7 & 16.7 & 1.2 & 3.6 & 1.2 & 11.3 & 4.0 \\
\hline $81-83$ & 153.4 & 44.0 & 3.4 & 40.1 & 42.5 & 14.2 & 11.0 & 0.9 & 1.2 & 0.7 & 12.9 & 2.1 \\
\hline $91-93$ & 142.6 & 33.9 & 4.1 & 41.6 & 43.9 & 18.4 & 11.6 & 1.3 & 2.5 & 1.8 & 12.7 & 3.8 \\
\hline $01-03$ & 168.5 & 14.0 & 6.6 & 78.1 & 54.3 & 31.2 & 21.1 & 2.5 & 9.2 & 3.0 & 28.2 & 9.2 \\
\hline $11-13$ & 164.8 & 17.5 & 15.3 & 116.6 & 71.7 & 62.3 & 33.3 & 3.7 & 16.1 & 3.2 & 21.9 & 17.1 \\
\hline
\end{tabular}

Source: FAOstat website: http://www.fao.org/faostat/en/\#data/FBS

Except for rice and roots, food availability per person in most food groups increased significantly in Vietnam since the 1960s (Table 1). Between 1961 and 2013, the supply of milk and milk products increased the most $(\sim 750 \%)$. This is followed by legumes nuts and seeds, meat, (all at nearly $400 \%$ increase) (Fig. 1). Notably, the availability of fruits and vegetables increased sharply in recent years, with combined availability of $188 \mathrm{~kg} /$ capita/year (over $500 \mathrm{~g}$ per person per day), comfortably exceeding the WHO/FAO minimum recommendation of $400 \mathrm{~g}$ if shared equitably (World Health Organisation 2003). Availability of meat however now exceeds maximums for human and climate health, suggested at $62 \mathrm{~kg}$ per person per year (McMichael et al. 2007).

Availability of the key foods driving a nutrition transition also rose sharply over this time: oils and fats rose by $\sim 400 \%$, beverages rose by $380 \%$, sugar and sweets rose by $176 \%$ ) (Fig. 1). Vietnam is a major sugar-producing country, although its sugar tends to be more expensive domestically than imported sugar; this means that the country is seen as growth market for sugar products and foreign companies have largely driven the $26 \%$ value growth in the retail of sugar between 2012 and 2017, even though the volume of sales stayed largely static over that time period (Euromonitor International 2018a, 2018b, 2018c, 2018d, 2018e). Over the same period, Vietnam has seen a switch from animal to vegetable oils due to their perceived health benefits and lower cost, and a switch from blended to single-seed oils again due to perceived health benefits; both the volume and value of edible oil sales rose by $30 \%$ between 2013 and 2018, largely driven by palm and soy oils, though olive oils saw the largest value growth (Euromonitor International 2018a, 2018b, 2018c, 2018d, 2018e). The increased availability of milk is a double-edged sword for nutrition in Vietnam, as it is increasingly available as fresh or dried whole-milk but also as other (mostly sweetened) milk products such as milkshakes, yoghurt and juice-milk combinations (Euromonitor International 2018a, 2018b, 2018c, 2018d, 2018e).
Fig. 1 Percent change in food supply ( $\mathrm{kg} /$ capita/year), 19612013. Source: Authors' own analysis, based on FAO Food Balance Sheet data 1961-2013. FAOstat website: http://www.fao. org/faostat/en/\#data/FBS

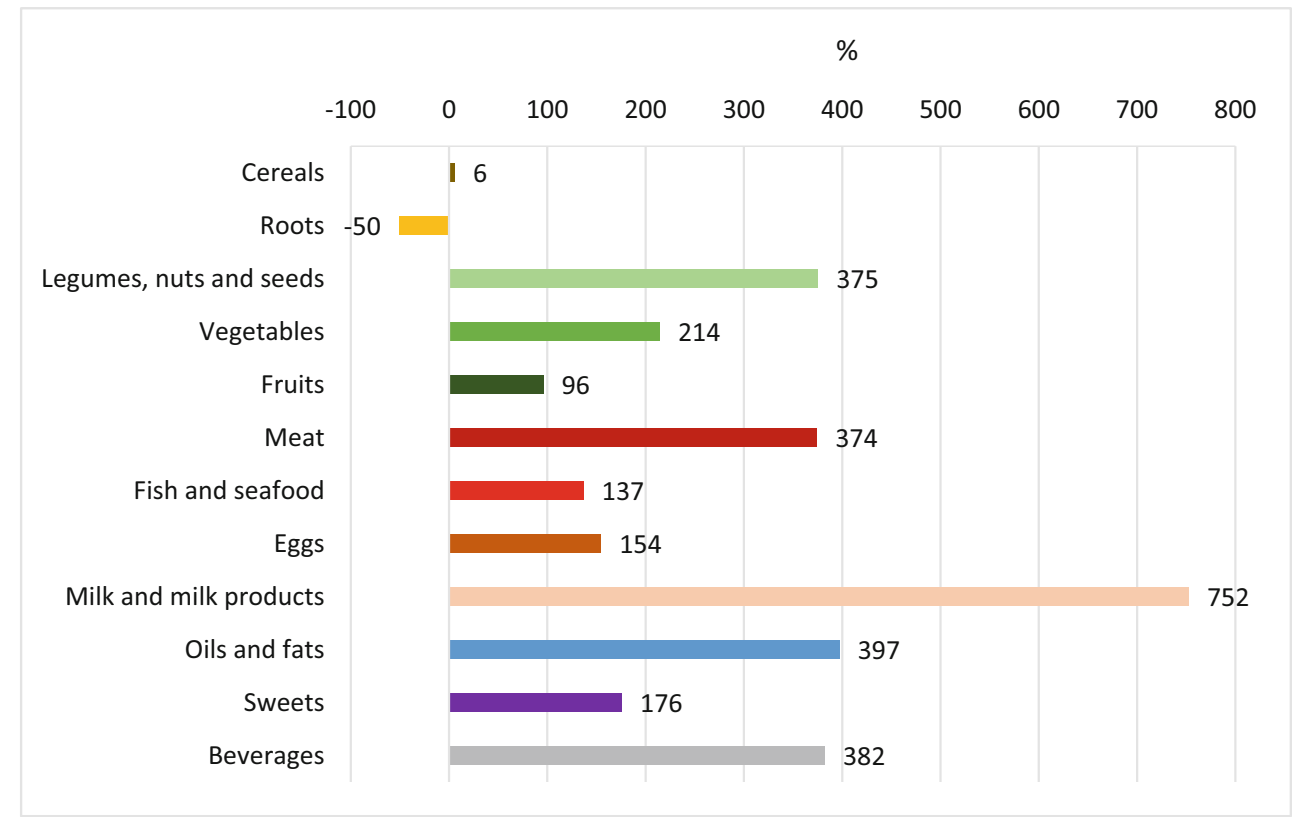


Overall at national level, Vietnam has managed to reduce its energy deficit and increase supply of nutritious foods, at the same time as increasing availability of foods high in sugars and fats.

\subsection{Changing food prices}

Large increases in food prices seen in Asia in 2007-8 were attributed largely to biofuel policies driving the grain prices up. These macroeconomic effects favoured the rice-exporting countries such as Vietnam (and rice producing households), but the urban poor and landless workers were negatively affected (Brahmbhatt and Christiaensen 2008). In Vietnam, an average household spends $43 \%$ of total expenditures on food, and $47 \%$ of the poor are net buyers of food, largely small rural landholders (Brahmbhatt and Christiaensen 2008). Prices in wet-markets with local production links tend to be lower, and around $85 \%$ of fresh food sales in Vietnam are through these markets (Euromonitor International 2018a, 2018b, 2018c, 2018d, 2018e).

While grain prices have recovered from peaks in 2008 and 2011, food prices changed significantly between 1996 and 2015 in Vietnam. In absolute terms, the prices of most of the foods we assessed have increased substantially (Fig. 2a). In particular, beef and buffalo meat increased the most (by over 92\%). Other cereals and beans also increased by between 26 and $68 \%$. In relative terms, the price data shows that many foods became more expensive over time in relation to rice, the staple food in Vietnam (Fig. 2b). While the price of mangoes and oranges remained reduced over time relative to rice, the price of other foods has increased by $10-60 \%$. Especially the price of sweet potato and buffalo increased by 95 and $124 \%$ relative to rice price, respectively. Conversely, the price for cane sugar reduced by $46 \%$ overall and by $37 \%$ relative to rice, making sugary foods cheaper to produce.

While the foods shown here are only markers for their broader food groups, and data were not available for many of the foods associated with the nutrition transition, these data show that it is becoming more expensive to diversify away from the staple food to a diverse diet, while sugar has become much more affordable over time.

\subsection{Changing household food expenditures}

Our analysis of nationally-representative data shows clear changes to household food expenditure patterns in Vietnam over time, and these changes were different in rural and urban areas and in groups with different economic status. Overall, between 2002 and 2014, household expenditure share on staple foods reduced, while expenditure share on fruits and vegetables increased substantially. Many of these changes were more pronounced in rural areas (Fig. 3). For example, the share spent on staple food reduced 18.4 percentage points in rural areas (from 39.3 to $20.8 \%$ ), much more than in urban areas at 9.1 percentage points (from 22.5 to $13.4 \%$ ). In addition, while the expenditure share on meat is stable in urban areas, it increased in rural areas (24.3 to $30.9 \%$ ).

A similar pattern plays out in differences between richer and poorer households (Fig. 4), where the expenditure share in the bottom quintile of households decreased substantially on starchy staple foods between 2002 and 2014, from 51.6\% to $29.1 \%$ and the expenditure by the richest quintile of households fell from $20.8 \%$ to $12.3 \%$. At the same time, expenditure in the poorest households on meat increased substantially (17.9 to $26.7 \%$ ), while expenditure on meat remained stable in richer households (at $34 \%$ ). Expenditure on sweets increased markedly in all socio-economic groups.

The expenditure share on food eaten away from home increased over time in both urban and rural areas and richer and poorer income groups. Though expenditure shares are larger in urban (30.4\% in 2014, up from $22.4 \%$ in 2002) and richer (30\%, up from $22 \%$ ) populations, shares have increased faster in rural (8.7\% in 2002 to $18.8 \%$ in 2014) and poorer (2.8\% to $11.6 \%$ ) populations (data not shown). This category is not disaggregated by food groups or by type of food, so it includes both processed 'fast foods' and traditional restaurant and street foods.

\subsection{Changing diets}

Food consumption patterns have changed significantly over time in Vietnam. The Vietnamese diet traditionally consists of high glycaemic-index carbohydrates (white rice and noodles) and high-sodium fish sauce, alongside fresh vegetables and meat. Between 1985 and 2010, the daily intake of the starchy staple foods rice (from 458 to $373 \mathrm{~g} /$ capita/day) and tubers (from 68.2 to $4.1 \mathrm{~g} / \mathrm{capita} /$ day) reduced significantly (Table 2). In contrast, the intakes of most other food groups substantially increased. Specifically, meat intake increased nearly eight-fold (from 11 to $84 \mathrm{~g} /$ person/day); fish intake almost doubled (from 35 to $60 \mathrm{~g} /$ person/day); and milk and egg intake increased more than 30-fold (from 0.8 to $29.5 \mathrm{~g} /$ person/day - likely largely driven by increases in milk products judging by the changes seen in food supply above). While the consumption of fruits increased substantially (from 2 to $61 \mathrm{~g} /$ person/day), the consumption of vegetables decreased from $214 \mathrm{~g}$ in 1985 to $171 \mathrm{~g}$ in 1989 and slightly increased after that. A 2015 STEPS survey found that Vietnamese adults (aged 18-69) typically consumed fruits 4 days per week and vegetables every day, with $57 \%$ reporting consumption of five servings of fruits and vegetables per day (General Department of Preventive Medicine 2016).

Oil and fat consumption increased significantly over 25 years, from $1.6 \mathrm{~g}$ in 1985 to $8 \mathrm{~g}$ in 2010 , and sugar consumption also increased, though respondents reported lower consumption in 2009 (3.8 g/day) than 2000 (7.8 g/day) 
Fig. 2 Prices - \% change 19962015. Source: FAOstat website: http://www.fao.org/faostat/en/\# data/PP a. Absolute change

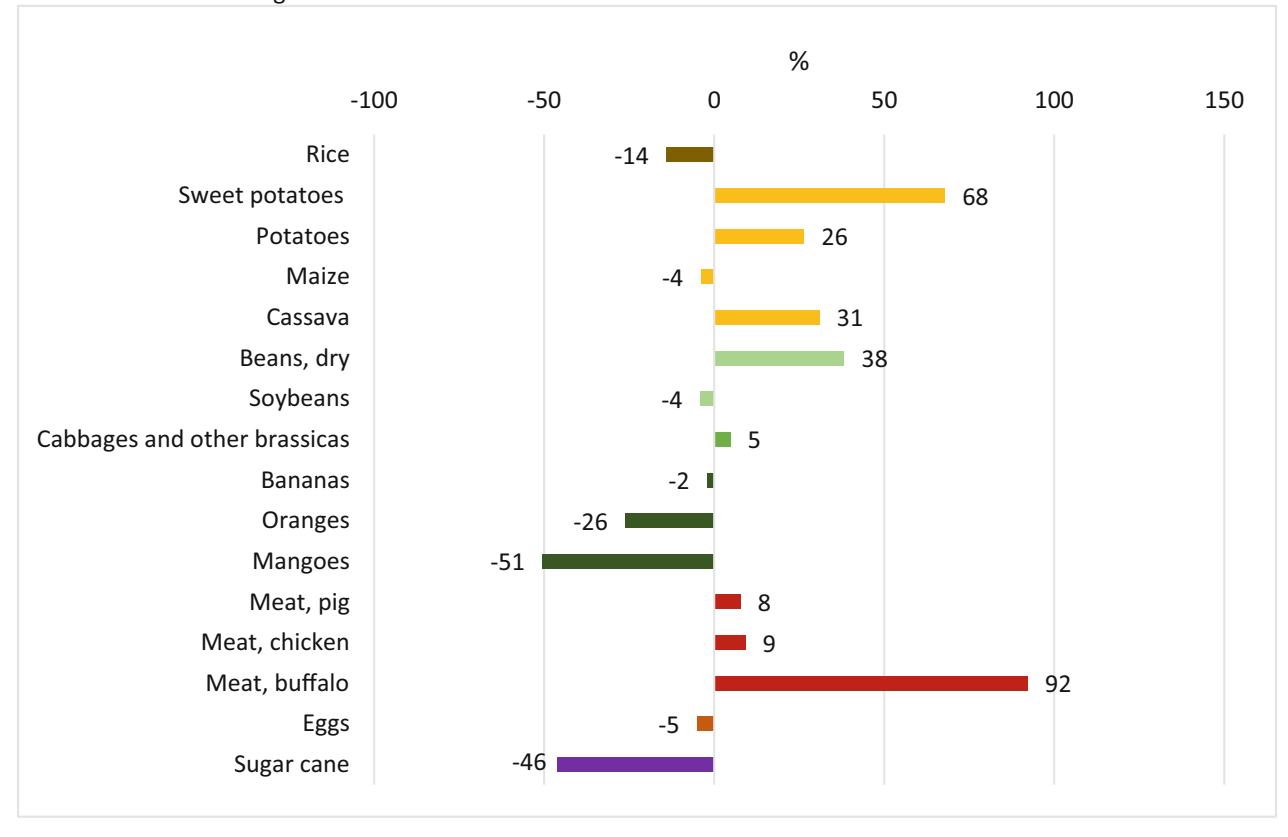

b. Relative change (to rice price)

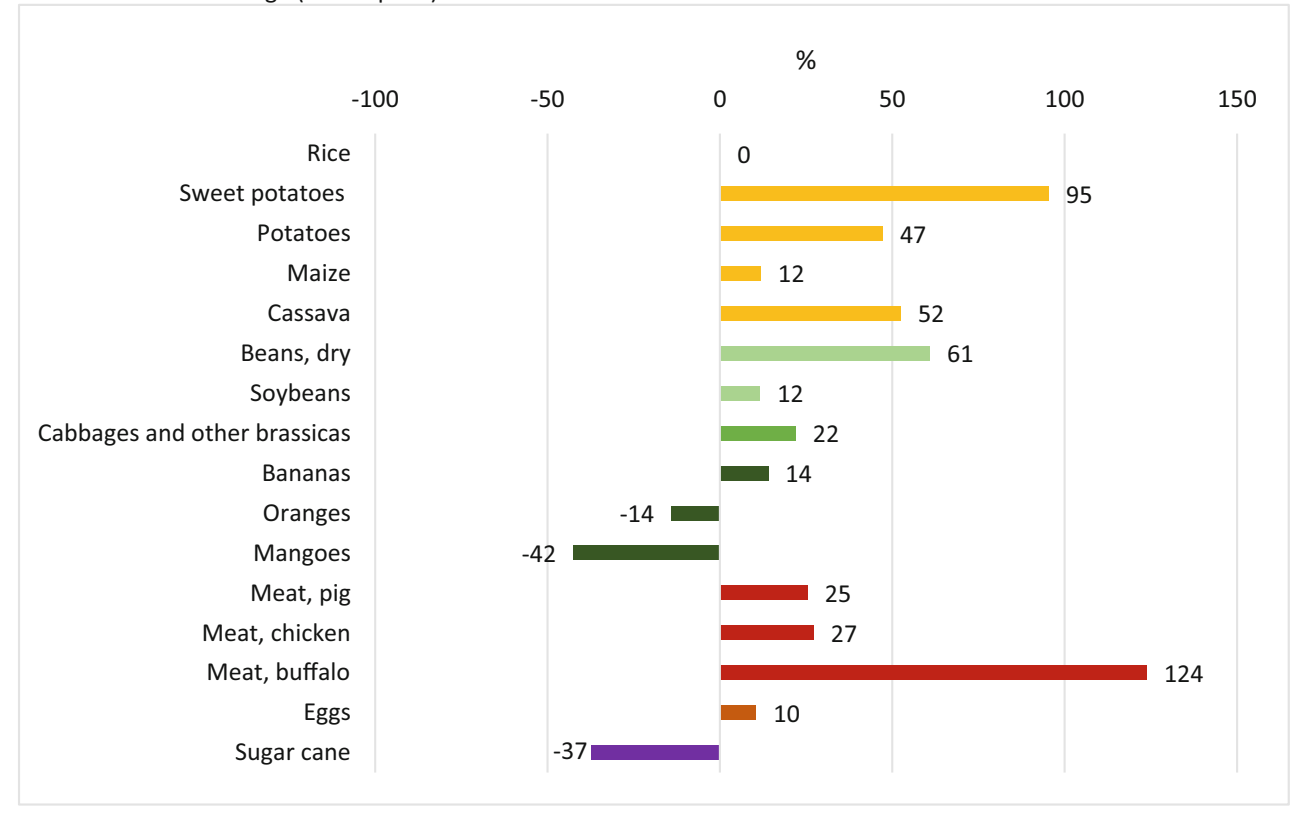

(Fig. 5). In addition, 10\% of the STEPS respondents reported eating processed foods high in salt every day or often (General Department of Preventive Medicine 2016). While primary data on the consumption of processed foods associated with NCDs, were not available previous studies in Vietnam have seen expenditures on highly processed foods range from $11 \%$ of food expenditure in poorer rural households, to $37 \%$ in richer urban households (Reardon et al. 2014).

The total energy intake was unchanged from 1985 to 2010 ( $\sim 1925 \mathrm{kcal}$, results not shown), but macronutrient constituents of diets have changed proportionally, reducing the proportion of energy from carbohydrate (83 to 66\%) and increasing the proportion of energy from protein (11 to $16 \%$ ) and fat (6 to $18 \%$ ) (Fig. 5). Similar patterns are shown in Fig. 6 where energy intake from rice reduced substantially, replaced by energy intake from animal source foods and other food groups.

While these data do not capture nuances such as ultraprocessed food or micronutrient consumption, it is clear that alongside continued consumption of nutrient-dense fruits, vegetables, meat and beans, populations in Vietnam are also increasing consumption of fats and sugars and salt, and increasing non-traditional foods such as milk in various fresh and sweetened forms. 
Fig. 3 Rural and Urban

Household Expenditure shares on different Food Groups. Source:

Authors' Computation from:

GSO: Household living standards survey 2014

Fig. 4 Richer and Poorer -

Household Expenditure shares on different Food Groups. Source:

Authors' Computation from: GSO: Household living standards survey 2014
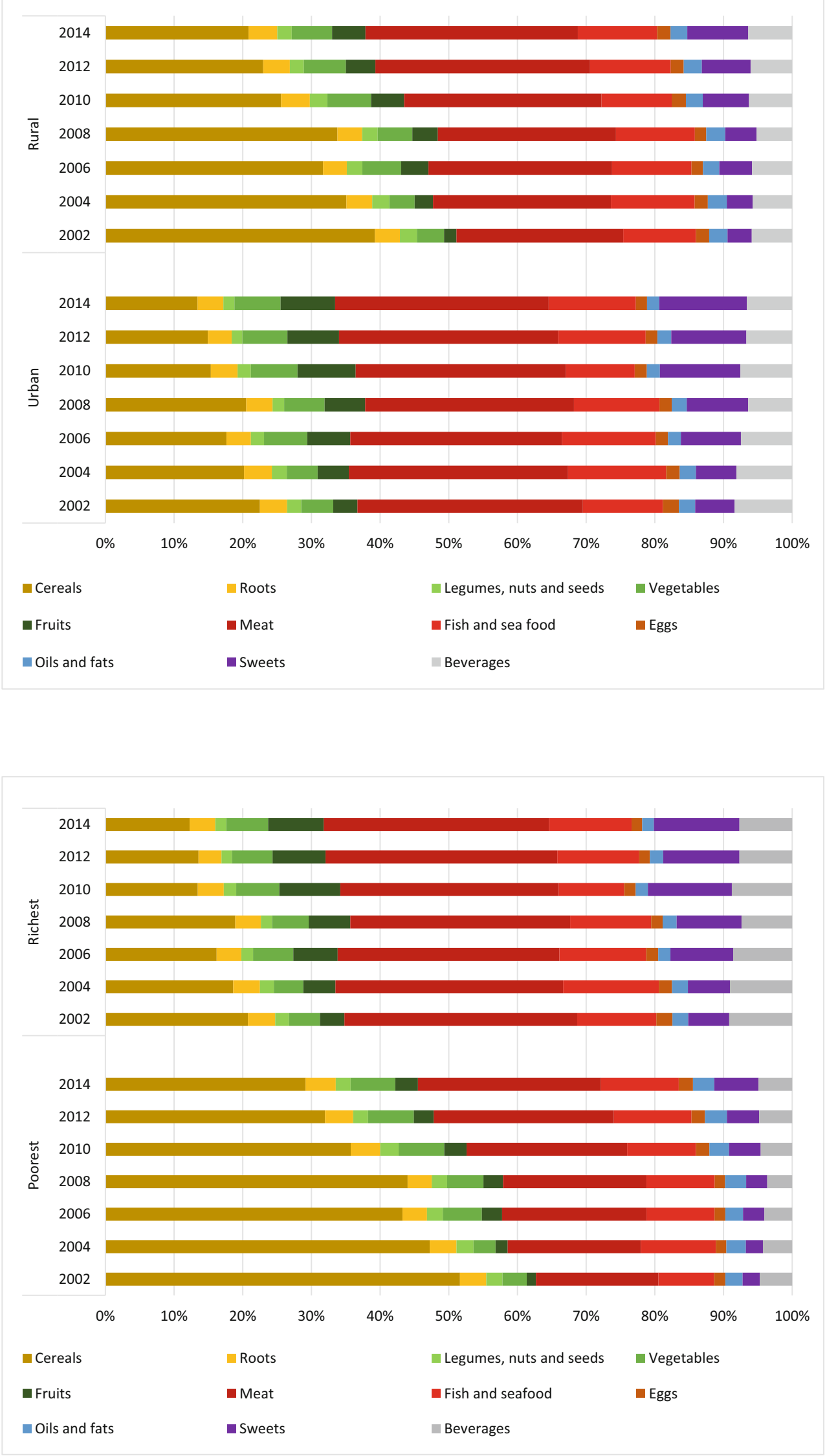
Table 2 Food consumption per capita per day (g/capita/day)

\begin{tabular}{lllll}
\hline & 1985 & 1989 & 2000 & 2009 \\
\hline Cereal & 458.0 & 452.0 & 397.0 & 373.2 \\
Roots & 68.2 & 37.6 & 8.9 & 4.1 \\
Vegetables & 214.0 & 171.3 & 178.6 & 190.4 \\
Fruits & 2.2 & 4.1 & 62.4 & 60.9 \\
Tofu/ beans/peas & 2.4 & 9.6 & 19.4 & 19.5 \\
Pulse/nuts & 3.0 & 3.8 & 4.3 & 4.5 \\
Meat & 11.1 & 24.4 & 51.0 & 84 \\
Fish & 35.0 & 41.2 & 45.5 & 59.8 \\
Egg and Milk & 0.8 & 2.9 & 10.3 & 29.5 \\
Oils and fats & 1.6 & 3.0 & 6.8 & 8.0 \\
Sweets & 0.9 & 0.8 & 7.8 & 3.8 \\
\hline
\end{tabular}

Source: NIN - General nutrition survey 2010

\subsection{Changing nutrition outcomes}

Vietnam is internationally noted for successfully reducing maternal and child undernutrition, particularly stunting, though pockets of very high prevalence remain among marginalized ethnic minority communities (Thang and Popkin 2003, Baulch et al. 2010). Between 2000 and 2014, stunting among children below 5 years declined from $36.5 \%$ to $24.9 \%$, and underweight among women of reproductive age reduce nearly by half (from 28.5 to $15.1 \%$ ) (Figure 7).

At the same time however overweight and its attendant chronic diseases are emerging issues in Vietnam. Nationally, the issue of overweight initially emerged in the late 1990s, more than doubling between 1992 and 2002, though from a low base (2\% to $5.7 \%)$. This is seen in all sections of the population but particularly among older (over 18), richer, female, white-collar, and urban sections of the population (Cuong et al. 2006, Nguyen et al. 2007, Tuan T Nguyen and
Hoang 2018). Overweight is also increasingly seen in children, with $5 \%$ of children under 5 overweight, and $4 \%$ of adolescents obese (GNR 2018). Some studies have found up to $37 \%$ of children obese in some schools in the major cities (Dieu et al. 2009; Nguyen et al. 2013; Do et al. 2015). Overweight and obesity has continued to increase in adults also (from 3.5\% to $15 \%$ since 2000) (Fig. 7). These changes co-exist with persistent undernutrition, creating a double burden in some contexts (Van Lierop et al. 2008), though Vietnam sees low levels of co-existence of stunted children and overweight mothers in the same households so far, with these outcomes occurring in different populations (Barnett 2004).

Nutrition-related chronic diseases such as hypertension, diabetes and high cholesterol have also emerged as significant issues, particularly among the urban rich (Khan and Khoi 2008). As in many other developing countries, noncommunicable diseases such as high blood pressure, elevated blood cholesterol and diabetes are rising (Fig. 7) and these figures are broadly mirrored in the STEPS survey findings (General Department of Preventive Medicine 2016). In 2010, nutrition-related chronic diseases (including cardiovascular diseases, cancers, and diabetes mellitus) accounted for $72 \%$ of total deaths in Vietnam, along with million 14 million disability-adjusted life years (Tuan T Nguyen and Hoang 2018).

\section{Discussion}

Using available data from different sources, our study is unique in examining food system drivers and different pathways of a nutrition transition through food supply, food prices, household food expenditures, diets, and nutrition outcomes in Vietnam. Through the analysis and synthesis presented above,
Fig. 5 Changes in composition of dietary energy sources. Source: NIN - General nutrition survey 2010

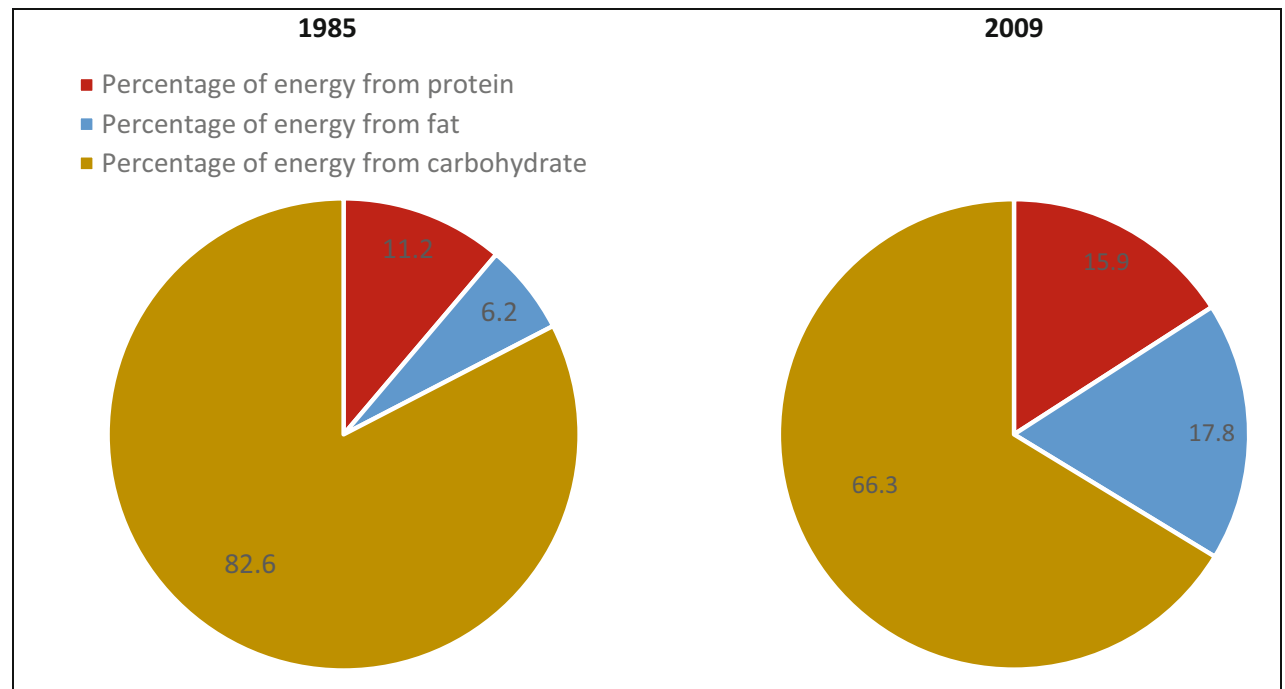


Fig. 6 Changes in composition of dietary energy sources, by food groups. Source: NIN - General nutrition survey 2010 a. 1990

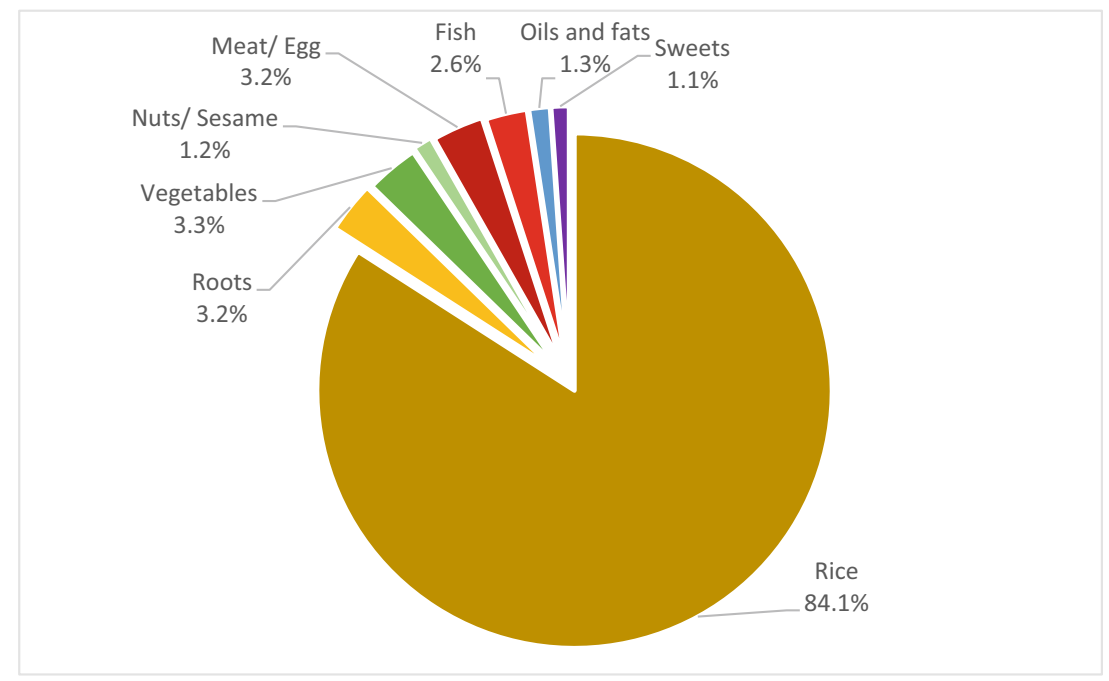

b. 2010

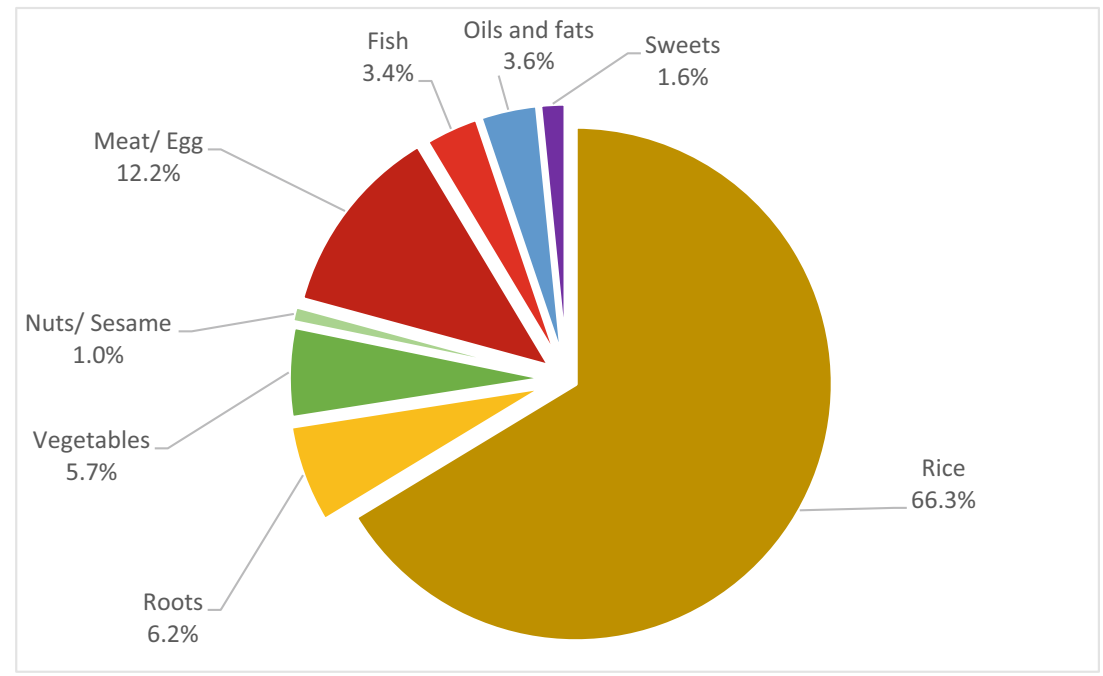

we are able to identify some potential food system drivers and food system changes towards a nutrition transition in Vietnam. Our findings show that while Vietnam is at the start of its nutrition transition, nutrition change is happening rapidly, and these food system drivers of the nutrition transition should be acknowledged and addressed in policy.

In terms of changes in healthful foods (those rich in micronutrients and fibre), the supply of vegetables and to a lesser extent fruits is plentiful, at least at a national level. This is in contrast to similar studies in other contexts, where supply of these is low (Harris et al. 2019), moderating the opportunity for healthy diets. While expenditure on vegetables in Vietnam remains consistent and small, vegetable consumption has dropped: combined fruit and vegetable supply is over $500 \mathrm{~g} /$ person/day, but reported intake is around half of that. Meat and milk are double-edged swords for nutrition in Vietnam
(Raneri et al. 2019): while they contain important micronutrients and are useful in the diet in small amounts and particularly for undernourished populations, too much red meat is associated with the diseases of the nutrition transition, and much of the milk sold in Vietnam is processed into sweetened products and beverages contributing to obesity and diabetes.

In terms of foods associated with the negative sides of the nutrition transition, the availability of sweets and sweetened beverages has risen in recent years, with oils and fats rising less, and consumption of sugars and fats has increased. The consumption of ultra-processed foods in particular is increasing rapidly in Asia, driven largely by trans-national food and beverage corporations, with carbonated sugar-sweetened drinks leading sales (Baker and Friel 2014; Baker and Friel 2016). We do not have data specifically on ultra-processed 


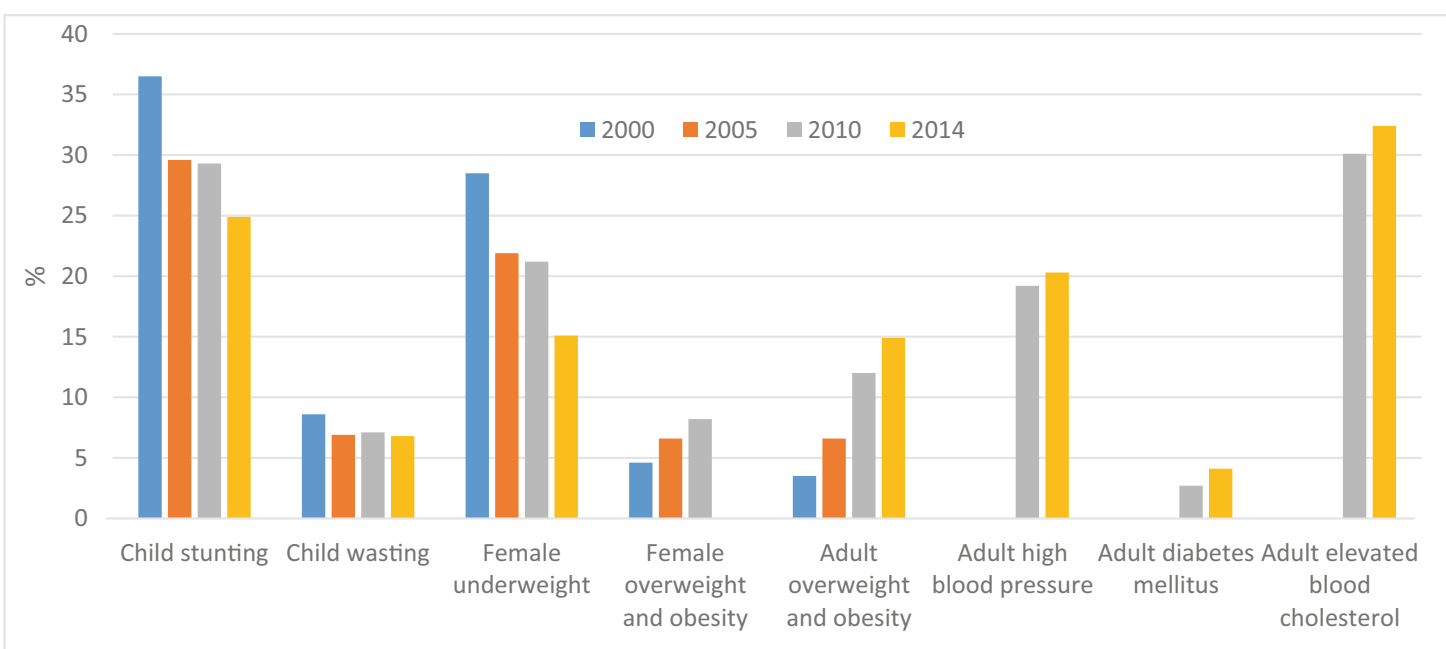

Fig. 7 Trends in selected nutrition and NCD outcomes. Source: NIN - The statistics on child malnutrition over the years 1999-2015, National nutrition surveillance and nutrition profile. Data for NCDs comes from Tuan T Nguyen and Hoang (2018)

foods, and these should be tracked as a priority in future diet and food systems research. Expenditure share on food eaten away from home, in many contexts a marker for less healthful diets, increased over time in all groups, though expenditure shares are larger in urban and richer populations.

While these changes are typical of a nutrition transition, Vietnam is also somewhat of an outlier in some respects: While undeniably obesity and NCDs are rising along with significant penetration of convenience stores and of highly processed foods and sugar-sweetened beverages (particularly in urban areas but also in rural parts), wet markets and daily fresh food purchases continue to dominate food purchasing behaviour. In addition, food eaten away from home means a different thing in a country renowned for its diverse and healthy street food and roadside restaurant culture which is in general cheap, convenient, varied and nutritious: Vietnam is an outlier in terms of both the amount and the quality of food eaten away from home in analyses, with much vegetable, meat and grain consumption 'hidden' in the category of 'food eaten away from home' in many surveys (Reardon et al. 2014).

In terms of convenience foods and foods eaten away from home, Vietnam shows a different trend to other countries in the region, with a lower transnational food service sector (international 'fast foods') than other regional countries, though the share of US companies is still growing here (Hanoi's first McDonalds opened in late 2017) while it has levelled in other countries in the region (Baker and Friel 2016). In this sense, Vietnam might be following in the footsteps of South Korea, where lower rates of obesity and NCDs than would be expected for its economic position have been attributed to maintenance of nutritious traditional diets alongside some of the more detrimental changes to food acquisition and consumption (Lee et al. 2002).
These changes in Vietnam's diets and nutrition are not unanticipated, with national nutrition policy recognising the nutrition transition as an emerging issue. New health policy has explicit targets for obesity reduction and activities focused on raising awareness of healthy diets and adequate food labelling to improve consumer choices (Policy 20-NQ/TW). Strategies go beyond the health sector, including healthy school meals and boosting agricultural production (Policy 6/CT-TTg).

This work on the food system drivers of the nutrition transition points to the need to further adapt policy in other sectors beyond health, however. Rice remains important, and keeping rice available and rice prices reasonable allows the poorest to more easily diversify out of the staple and into more nutritious foods (Gibson and Kim 2013). Cassava is also an important food security crop particularly in highland areas where ethnic minorities with poorer nutrition live, with similar implications. Beyond staple foods however, making nutrient-rich foods more accessible and nutrient-poor or ultra-processed foods less accessible is important if additional income is to contribute to a healthy diet (Bairagi et al. 2020).

It has been suggested that both agricultural production policies and food price policies are important in limiting availability and accessibility of foods such as refined oils (Popkin et al. 2001), and the extent to which these policies are constrained by macroeconomic and trade policies to which Vietnam is a signatory should be investigated (Thow et al. 2015). The active promotion of traditional diets in countries where these are generally healthy, such as Vietnam, through mass media or schools has been seen to hold down the worst of the transition in countries such as Thailand, Singapore and South Korea (Popkin et al. 2001), and the limiting of aggressive marketing of ultra-processed food might contribute to limiting dietary change (Pham et al. 2016). Ensuring that 
families, teachers and health professionals are adequately armed with knowledge is important (Pham et al. 2016), but the analyses above show that food system drivers of the nutrition transition require the modulation of supply and access as much as demand.

The key drivers of food system change expected to produce the nutrition transition are in place in Vietnam: Economic growth, urbanisation, changing food production and trade, changing food sources, and changing preferences and food cultures are driving change in different parts of the food system. The food system determinants of changing diet and nutrition outcomes therefore need to be acknowledged, understood and addressed throughout multiple sectors of policy in Vietnam before the nutrition transition becomes entrenched.

\section{Compliance with ethical standards}

Conflict of interest The authors declare that they have no conflict of interest.

Open Access This article is licensed under a Creative Commons Attribution 4.0 International License, which permits use, sharing, adaptation, distribution and reproduction in any medium or format, as long as you give appropriate credit to the original author(s) and the source, provide a link to the Creative Commons licence, and indicate if changes were made. The images or other third party material in this article are included in the article's Creative Commons licence, unless indicated otherwise in a credit line to the material. If material is not included in the article's Creative Commons licence and your intended use is not permitted by statutory regulation or exceeds the permitted use, you will need to obtain permission directly from the copyright holder. To view a copy of this licence, visit http://creativecommons.org/licenses/by/4.0/.

\section{References}

Afshin, A., Sur, P. J., Fay, K. A., Cornaby, L., Ferrara, G., Salama, J. S., Mullany, E. C., Abate, K. H., Abbafati, C., \& Abebe, Z. (2019). Health effects of dietary risks in 195 countries, 1990-2017: A systematic analysis for the global burden of disease study 2017. The Lancet, 393(10184), 1958-1972.

Bairagi, S., Mohanty, S., Baruah, S, \& Thi, H. T. (2020). Changing food consumption patterns in rural and urban Vietnam: Implications for a future food supply system. Australian Journal of Agricultural and Resource Economics, 64(3), 750-775.

Baker, P., \& Friel, S. (2014). Processed foods and the nutrition transition: Evidence from Asia. Obesity Reviews, 15(7), 564-577.

Baker, P., \& Friel, S. (2016). Food systems transformations, ultraprocessed food markets and the nutrition transition in Asia. Globalization and Health, 12(1), 80.

Barnett, T. (2004). Editorial: The cost of an HIV/AIDS epidemic. Tropical Medicine \& International Health, 9(3), 315-317.

Baulch, B. (2016). "Explaining catch-up in human development: A political economy comparisons on the Philippines and Viet Nam since 1986." The Kellogg Institute for International Studies: Working paper 412.

Baulch, B., Nguyen, T. M. H., Nguyen, T. T. P., \& Pham, T. H. (2010). Ethnic minority poverty in Vietnam. Washington DC: World Bank.

Beal, T., Le, T. D., Trinh, H. T., Burra, D. D., Béné, C., Huynh, T. T. T., Truong, M. T., Nguyen, S. D., Tran, D. T., \& Nguyen, K. T. (2020).
Child overweight or obesity is associated with modifiable and geographic factors in Vietnam: Implications for program design and targeting. Nutrients, 12(5), 1286.

Black, R. E., Victora, C. G., Walker, S. P., Bhutta, Z. A., Christian, P., Onis, M. D., Ezzati, M., Grantham-McGregor, S., Katz, J., Martorell, R., Uauy, R., \& the Maternal and Child Nutrition Study Group. (2013). Maternal and child undernutrition and overweight in low-income and middle-income countries. Lancet, 382(9890), 427-451.

Bloem, S., \& de Pee, S. (2017). Developing approaches to achieve adequate nutrition among urban populations requires an understanding of urban development. Global Food Security, 12, 80-88.

Bloom, D. E., \& Williamson, J. G. (1998). Demographic transitions and economic miracles in emerging Asia. The World Bank Economic Review, 12(3), 419-455.

Brahmbhatt, M., \& Christiaensen, L. (2008). Rising food prices in East Asia: Challenges and policy options. Washington DC: World Bank.

Chicago Council on Global Affairs. (2011). Bringing agriculture to the table: How agriculture and food can play a role in preventing chronic disease. Chicago Council on Global Affairs: Chicago.

Chisanga, B. and Mbata-Zulu, O. (2017). The changing food expenditure patterns and trends in Zambia: Implications on agricultural policies. Indaba agricultural policy research institute working paper no. 119. Lusaka, Zambia, IAPRI.

Cook, S. (2017). Nourishing diversity: A five-point plan to enrich our food systems. Hivos Briefing Paper. London, HIVOS and IIED.

Crush, J., Frayne, B. and McLachlan, M. (2011). Rapid urbanization and the nutrition transition in southern Africa. Urban food security series no. 7. Kingston and Cape Town, Queen's University and AFSUN.

Cuong, T. Q., Dibley, M. J., Bowe, S., Hanh, T. T. M., \& Loan, T. T. H. (2006). Obesity in adults: An emerging problem in urban areas of Ho Chi Minh City, Vietnam. European Journal of Clinical Nutrition, 61, 673.

Dieu, H. T. T., Dibley, M. J., Sibbritt, D. W., \& Hanh, T. T. M. (2009). Trends in overweight and obesity in pre-school children in urban areas of Ho Chi Minh City, Vietnam, from 2002 to 2005. Public Health Nutrition, 12(5), 702-709.

Do, L. M., Tran, T. K., Eriksson, B., Petzold, M., Nguyen, C. T., \& Ascher, H. (2015). Preschool overweight and obesity in urban and rural Vietnam: Differences in prevalence and associated factors. Global Health Action, 8(1), 28615.

Euromonitor International. (2018a). Edible oils in Vietnam. Euromonitor Passport Reports.

Euromonitor International. (2018b). Fresh food in Vietnam. Euromonitor Passport Reports.

Euromonitor International. (2018c). Other dairy in Vietnam. Euromonitor Passport Reports.

Euromonitor International. (2018d). Packaged foods in Vietnam. Euromonitor Passport Reports.

Euromonitor International. (2018e). Sugar and sweeteners in Vietnam. Euromonitor Passport Reports.

FANTA. (2006). Household dietary diversity score (HDDS) for measurement of household food access: Indicator guide VERSION 2. Washington, DC: AED.

General Department of Preventive Medicine. (2016). "Announcing the results of the national investigation of risk factors for non-communicable disease in 2015." Retrieved February 2019, from http://vncdc.gov.vn/vi/ tin-tuc-trong-nuoc/1003/cong-bo-ket-qua-dieu-tra-quoc-gia-yeu-tonguy-co-benh-khong-lay-nhiem-nam-2015.

General Satistics Office of Vietnam (2009). "2009 census." Retrieved November 2018, from https://www.gso.gov.vn/default_en.aspx? tabid $=599 \&$ ItemID $=9788$

General Statistics Office of Vietnam. (multiple years) (n.d.). "Household Living Standards Survey." from http://www.gso.gov.vn/default en. aspx?tabid $=483 \&$

Gibson, J., \& Kim, B. (2013). Quality, quantity, and nutritional impacts of rice price changes in Vietnam. World Development, 43, 329-340. 
Gillespie, S., \& van den Bold, M. (2017). Agriculture, food systems, and nutrition: Meeting the challenge. Global Challenges, 1(3).

Global Panel on Agriculture and Food Systems for Nutrition. (2016). Food systems and diets: Facing the challenges of the 21st century. London: Global Panel.

Gygli, S., Haelg, F., Potrafke, N. and Sturm, J.-E. (2019). "The KOF globalisation index - Revisited." The Review of International Organizations.

Hansen, A. (2018). Meat consumption and capitalist development: The meatification of food provision and practice in Vietnam. Geoforum, 93, 57-68.

Harris, J., Chisanga, B., Drimie, S., \& Kennedy, G. (2019). Nutrition transition in Zambia: Changing food supply, food prices, household consumption, diet and nutrition outcomes. Food Security, 11(2), 371-387.

Harris, J., Hyrnick, A., Mai, T. M. T., Huynh, T., Huynh, P., Nguyen, P. and Thow, A.-M. (forthcoming). "Trade and transition: Advocacy coalitions, trade policy, and negotiating space for nutrition in Vietnam." Health Policy and Planning.

Hawkes, C. (2006). Uneven dietary development: Linking the policies and processes of globalization with the nutrition transition, obesity and diet-related chronic diseases. Globalization and Health, 2(1), 4.

Hawkes, C. (2008). Dietary implications of supermarket development: A global perspective. Development and Policy Review, 26(6), 657-692.

Hawkes, C., Harris, J. and Gillespie, S. (2017). Changing diets: Urbanization and the nutrition transition. GLobal Food Policy Report 2017. Washington, DC, IFPRI: 34-41.

Hirvonen, K., Bai, Y., Headey, D. and Masters, W. A. (2019). "Cost and affordability of the EAT-lancet diet in 159 countries." Lancet.

HLPE. (2017). Nutrition and food systems. High Level Panel of Experts on Food Security and Nutrition of the Committee on World Food Security: Rome.

Imamura, F., Micha, R., Khatibzadeh, S., Fahimi, S., Shi, P., Powles, J., \& Mozaffarian, D. (2015). Dietary quality among men and women in 187 countries in 1990 and 2010: A systematic assessment. The Lancet Global Health, 3(3), e132-e142.

Kelly, M., Seubsman, S.-a., Banwell, C., Dixon, J., \& Sleigh, A. (2014). Thailand's food retail transition: Supermarket and fresh market effects on diet quality and health. British Food Journal, 116(7), 1180-1193.

Kennedy, G., Nantel, G. and Shetty, P. (2004). Globalization of food systems in developing countries: A synthesis of country case studies. Globalization of food systems in developing countries: Impact on food security and nutrition. Rome, FAO.

Khan, N. C., \& Khoi, H. H. (2008). Double burden of malnutrition: The Vietnamese perspective. Asia Pacific Journal of Clinical Nutrition, 17(S1), 116-118.

Lee, M.-J., Popkin, B. M., \& Kim, S. (2002). The unique aspects of the nutrition transition in South Korea: The retention of healthful elements in their traditional diet. Public Health Nutrition, 5(1a), 197-203.

Mai, T. M. T., Pham, N. O., Tran, T. M. H., Baker, P., Gallegos, D., Do, T. N. D., van der Pols, J. C. and Jordan, S. J. (2020). "The double burden of malnutrition in Vietnamese school-aged children and adolescents: a rapid shift over a decade in Ho Chi Minh City." European Journal of Clinical Nutrition 1-9.

McMichael, A. J., Powles, J. W., Butler, C. D., \& Uauy, R. (2007). Energy and health 5: Food, livestock production, energy, climate change, and health. Lancet (British edition), 370(9594).

Mehio Sibai, A., Nasreddine, L., Mokdad, A. H., Adra, N., Tabet, M., \& Hwalla, N. (2010). Nutrition transition and cardiovascular disease risk factors in Middle East and North Africa countries: Reviewing the evidence. Annals of Nutrition and Metabolism, 57(3-4), 193-203.

Mergenthaler, M., Weinberger, K., \& Qaim, M. (2009). The food system transformation in developing countries: A disaggregate demand analysis for fruits and vegetables in Vietnam. Food Policy, 34(5), 426-436.

Miller, V., Yusuf, S., Chow, C. K., Dehghan, M., Corsi, D. J., Lock, K., Popkin, B., Rangarajan, S., Khatib, R., Lear, S. A., Mony, P., Kaur, M., Mohan, V., Vijayakumar, K., Gupta, R., Kruger, A., Tsolekile, L., Mohammadifard, N., Rahman, O., Rosengren, A., Avezum, A.,
Orlandini, A., Ismail, N., Lopez-Jaramillo, P., Yusufali, A., Karsidag, K., Iqbal, R., Chifamba, J., Oakley, S. M., Ariffin, F., Zatonska, K., Poirier, P., Wei, L., Jian, B., Hui, C., Xu, L., Xiulin, B., Teo, K., \& Mente, A. (2016). Availability, affordability, and consumption of fruits and vegetables in 18 countries across income levels: Findings from the prospective urban rural epidemiology (PURE) study. The Lancet Global Health, 4(10), e695-e703.

Ministry of Health, National Institute of Nutrition and UNICEF. (2010). General nutrition survey 2009-2010. Hanoi: Vietnam, Medical Publishing House.

Misra, A., Singhal, N., Sivakumar, B., Bhagat, N., Jaiswal, A., \& Khurana, L. (2011). Nutrition transition in India: secular trends in dietary intake and their relationship to diet- related noncommunicable diseases. Journal of Diabetes, 3, 278-292.

Monteiro, C. A., Cannon, G., Moubarac, J.-C., Levy, R. B., Louzada, M. L. C., \& Jaime, P. C. (2018). The UN decade of nutrition, the NOVA food classification and the trouble with ultra-processing. Public Health Nutrition, 21(1), 5-17.

National Institute of Nutrition. (2015). The statistics on child malnutrition over the years 1999-2015, National nutrition surveillance and nutrition profile. Hanoi: National Institute of Nutrition.

Nguyen, T. T., \& Hoang, M. V. (2018). Non-communicable diseases, food and nutrition in Vietnam from 1975 to 2015: The burden and national response. Asia Pacific Journal of Clinical Nutrition, 27(1), 19-28.

Nguyen, M. D., Beresford, S. A. A., \& Drewnowski, A. (2007). Trends in overweight by socio-economic status in Vietnam: 1992 to 2002. Public Health Nutrition, 10(2), 115-121.

Nguyen, P. V. N., Hong, T. K., Hoang, T., \& Robert, A. R. (2013). High prevalence of overweight among adolescents in Ho Chi Minh City, Vietnam. BMC Public Health, 13(1), 141.

Nguyen, T. T., Roehrig, F., Grosjean, G., Tran, D. and Vu, T. (2017). "Climate Smart Agriculture in Vietnam".

Pham, Q. T., Worsley, A., Lawrence, M. and Marshall, B. (2016). "Opportunities and barriers to public health nutrition education in Vietnamese universities." Asia Pacific Journal of Clinical Nutrition.

Pingali, P. (2004). Westernization of Asian diets and the transformation of food systems: Implications for research and policy. ESA working paper no. 0417. Rome, the food and agriculture Organization of the United Nations.

Popkin, B. (1994). The nutrition transition in low-income countries: An emerging crisis. Nutrition Reviews, 52(9), 285-298.

Popkin, B. (1999). Urbanization, lifestyle changes and the nutrition transition. World Development, 27(11), 1905-1916.

Popkin, B. M. (2014). Nutrition, agriculture and the global food system in low and middle income countries. Food Policy, 47, 91-96.

Popkin, B. M., \& Gordon-Larsen, P. (2004). The nutrition transition: Worldwide obesity dynamics and their determinants. International Journal of Obesity, 28, S2-S9.

Popkin, B., Horton, S. and Kim, S. (2001). The nutritional transition and diet-related chronic diseases in Asia: implications for prevention.

Raneri, J. E., Kennedy, G., Nguyen, T., Wertheim-Heck, S., Do, H., de Haan, S. and Phuong, N. (2019). Determining key research areas for healthier diets and sustainable food systems in Viet Nam. International Food Policy Research Institute.

Reardon, T., Tschirley, D., Dolislager, M., Snyder, J., Hu, C., \& White, S. (2014). Urbanization, diet change, and transformation of food supply chains in Asia. Michigan: Global Center for Food Systems Innovation.

Rischke, R., Kimenju, S. C., Klasen, S., \& Qaim, M. (2015). Supermarkets and food consumption patterns: The case of small towns in Kenya. Food Policy, 52, 9-21.

Ruel, M., J. Garrett and L. Haddad (2008). Rapid urbanization and the challenges of obtaining food and nutrition security. Nutrition and health in developing countries (Second edition). R. Semba and M. Bloem. USA, Humana Press.

Ruel, M., Alderman, H., \& Maternal and Child Nutrition Study Group. (2013). Nutrition-sensitive interventions and programmes: How can 
they help to accelerate progress in improving maternal and child nutrition? Lancet, 382(9891), 536-551.

Schneider, A., Mertes, C., Tatem, A., Tan, B., Sulla-Menashe, D., Graves, S., Patel, N., Horton, J., Gaughan, A., \& Rollo, J. (2015). A new urban landscape in east-Southeast Asia, 2000-2010. Environmental Research Letters, 10(3), 034002.

Thang, N. M., \& Popkin, B. M. (2003). In an era of economic growth, is inequity holding back reductions in child malnutrition in Vietnam? Asia Pacific Journal of Clinical Nutrition, 12(4), 405-410.

Thow, A. M., Snowdon, W., Labonté, R., Gleeson, D., Stuckler, D., Hattersley, L., Schram, A., Kay, A., \& Friel, S. (2015). Will the next generation of preferential trade and investment agreements undermine prevention of noncommunicable diseases? A prospective policy analysis of the trans Pacific partnership agreement. Health Policy, 119(1), 88-96.

Trinh, H. T., Morais, J., Thomas-Agnan, C., \& Simioni, M. (2019). Relations between socio-economic factors and nutritional diet in Vietnam from 2004 to 2014: New insights using compositional data analysis. Statistical Methods in Medical Research, 28(8), 23052325.

USDA Foreign Agricultural Service (2017). Vietnam retail foods. GAIN Reports. Hanoi, Global Agricultural Information Network.

Van Esterik, P. (2008). Food culture in Southeast Asia, Greenwood Publishing Group.

Van Lierop, A., Nam, N. V., Doak, C., Hung, L. Q., Binh, T. Q., Hoekstra, J., \& De Vries, P. J. (2008). Regional clustering of anthropometric dimensions of primary school children in rural and suburban Vietnam. Asia Pacific Journal of Clinical Nutrition, 17(4), 603-607.

Wei, Y. D. (2017). Geography of inequality in Asia. Geographical Review, 107(2), 263-275.

Wertheim-Heck, S. C., \& Spaargaren, G. (2016). Shifting configurations of shopping practices and food safety dynamics in Hanoi, Vietnam: A historical analysis. Agriculture and Human Values, 33(3), 655671

World Bank. (2018). "World Bank country data: Vietnam." Retrieved November 2018, from https://data.worldbank.org/country/vietnam.

World Health Organisation (2003). Diet, nutrition and the prevention of chronic diseases. WHO technical report series 916. Geneva, WHO.

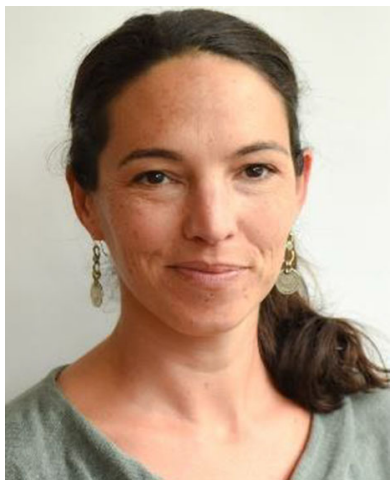

Dr Jody Harris is a Research Fellow at the Institute of Development Studies (IDS) in the UK and a Lead Expert on Food Systems at World Vegetable Center in Bangkok, Thailand. With a research interest in food and nutrition policy and politics, she has over a decade of experience in leading international nutrition research and practice. Her work includes qualitative and quantitative research and evaluations in various contexts in Asia and Sub-Saharan Africa, particularly Zambia and Vietnam.

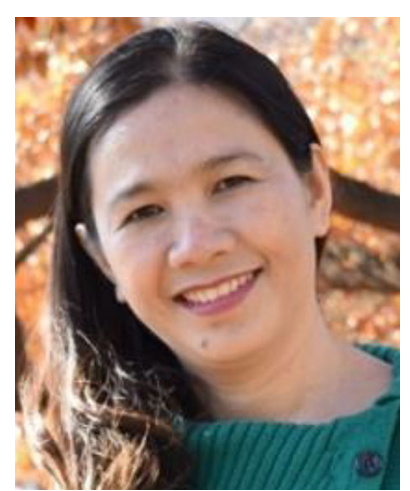

Dr Phuong Hong Nguyen is a Research Fellow in the Poverty, Health, and Nutrition Division at the International Food Policy Research Institute (IFPRI). Her research interests are in the areas of maternal and child health and nutrition. She has substantial experience in impact and process evaluation, as well as implementation and policy research in several countries including Bangladesh, Ethiopia, India and Vietnam.

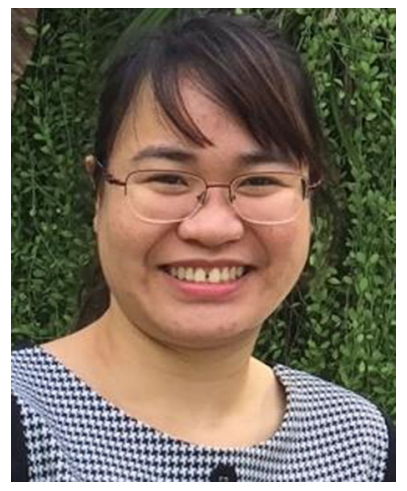

Ms Lan Mai Tran is a Technical Officer at the FHI360 in Hanoi, Viet Nam, focused on maternal and child nutrition. She has participated in various research and evaluations in Viet $\mathrm{Nam}$, Bangladesh and India for 10 years.

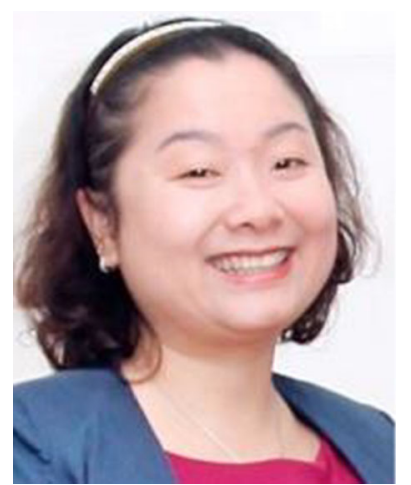

Dr Phuong Huynh is the Deputy Director of Food and Nutrition Training Centre at the National Institute of Nutrition Vietnam since 2013. She is a medical doctor and has MSc degree in reproductive and sexual health research and $\mathrm{PhD}$ in Nutrition. She is a nutrition researcher and a lecturer at Hanoi Medical University in the field of Infant and Young Child feeding and behaviour change communication. She has led many intervention projects with a multi-sectoral approach for improved nutrition. She has also led the development of a number of technical guidelines, such as Management of Child Acute Malnutrition, Nutrition for people with HIV/AIDS, Nutrition in emergency, Infant and Young Child feeding in Vietnam. She is the secretary of Scaling Up Nutiriton Movement in Vietnam and a focal person for many international cooperation programs (UNICEF, A\&T, Save the Children, FHI360). Currently, she is on the team for midterm review of Vietnam' national nutrition policy 2012-2016 and has been assigned as team leader to develop new NPAN 2017-2020 to be approved by the Prime Minister. 